\title{
Cyclosporine A and steroid therapy in childhood steroid-resistant nephrotic syndrome
}

This article was published in the following Dove Press journal: International Journal of Nephrology and Renovascular Disease 20 August 2010

Number of times this article has been viewed

\section{Gargah Tahar \\ Lakhoua M Rachid \\ Department of Pediatric Nephrology, Charles Nicolle Hospital, Tunis, Tunisia}

Correspondence: Gargah Tahar Department of Pediatric Nephrology, Charles Nicolle Hospital,

Boulevard 9 Avril,

Tunis 1006, Tunisia

Tel +216 2306 I5 I5

Email kitomora@yahoo.fr
Background: In children, idiopathic nephrotic syndrome (INS) is primarily treated using corticosteroids. When remission is not achieved, the coadministration of potent immunosuppressant therapy becomes imperative. Cyclosporine A (CsA) is reportedly associated with a higher incidence of remission in comparison with other immunosuppressive agents.

Methods: The present study investigated the response of combination therapy using CsA and prednisolone in 30 Tunisian children with idiopathic steroid-resistant nephrotic syndrome (ISRNS). Renal histopathology was compatible with focal segmental glomerular sclerosis (FSGS) in 15 children, minimal change disease (MCD) in nine children, and diffuses mesangiale proliferation (DMP) in six children.

Results: The therapy protocol produced a complete remission of proteinuria in 15 patients $(50 \%)$ and a partial remission in nine patients (30\%). Six patients $(20 \%)$ showed no response to therapy. Progression to end stage renal disease occurred in five CsA-resistant children and in four CsA-responsive patients. CsA-related nephrotoxicity was detected by renal biopsy in one patient.

Conclusions: CsA remains the primary cytotoxic treatment for childhood steroid-resistant nephrotic syndrome. Its use in combination with corticosteroids provides optimum efficiency without high risk of nephrotoxicity.

Keywords: children, corticosteroids, cyclosporine A, nephrotic syndrome.

\section{Introduction}

The management of steroid-resistant nephrotic syndrome (SRNS) remains a clinical problem. Several treatment modalities have been tested, including highdose corticosteroids, cyclophosphamide, cyclosporine A (CsA), and more recently, tacrolimus. Optimal combinations of medications with least toxicity remain to be determined. Treatment with a combination of oral prednisolone and oral CsA may lead to remission in a significant proportion of children. However, the long-term use of CsA exposes the patient to nephrotoxicity and requires clinical, biological, and histopathological monitoring.

Previously, many authors, in particular Niaudet, ${ }^{1}$ have reported the beneficial effect of a combination of oral prednisolone and oral CsA. This finding was confirmed by a recent multicenter study ${ }^{2}$ which demonstrated that CsA had a significantly higher rate of response than did cyclophosphamide pulse therapy. The present study was therefore performed to evaluate the effectiveness and safety of CsA in Tunisian children with idiopathic steroid-resistant nephrotic syndrome (ISRNS). 


\section{Patients and methods}

This retrospective study included all children with ISRNS who received the combined oral idiopathic $\left(\mathrm{Neoral}^{\circledR}\right.$ or Equora ${ }^{\circledR}$ ) and oral prednisone for the period between January 2002 and December 2008. Inclusion criteria were: (1) steroid resistance, either primary or secondary; (2) age at onset of nephrotic syndrome: $>1$ year and $<14$ years; (3) minimal follow-up period: 1 year; (4) diagnosis of idiopathic nephrotic syndrome since January 2002. Exclusion criteria were: (1) nephrotic syndrome underlying secondary causes; (2) patients with family history of SRNS; (3) congenital or syndromic forms of SRNS; (4) patients with creatinine clearance of less than $50 \mathrm{~mL} / \mathrm{min}$ per $1.73 \mathrm{~m}^{2}$.

\section{Definitions}

Nephrotic syndrome was defined as proteinuria $>50 \mathrm{mg} / \mathrm{kg}$ per 24 hours; or protein/creatinine $>3 \mathrm{mg} / \mathrm{kg}$ associated with hypoproteinemia $<60 \mathrm{~g} / \mathrm{L}$ and hypoalbuminemia $<30 \mathrm{~g} / \mathrm{L}$.

Steroid-resistance, either primary or secondary, was defined as a failure to achieve resolution of clinical and laboratory features of nephrotic syndrome after four weeks of daily prednisolone therapy $\left(60 \mathrm{mg} / \mathrm{m}^{2}\right)$ followed by three intravenous pulses of methyl-prednisolone at a dose of $1 \mathrm{~g} / 1.73 \mathrm{~m}^{2}$.

Complete remission was defined as a proteinuria level of less than $10 \mathrm{mg} / \mathrm{kg}$ per day. The remission was considered as partial when proteinuria was between 10 and $50 \mathrm{mg} / \mathrm{kg}$ per day, with a serum albumin greater than $30 \mathrm{~g} / \mathrm{L}$.

A relapse of nephrotic syndrome in patients who achieved complete or partial remission was defined as the reappearance of proteinuria greater than $50 \mathrm{mg} / \mathrm{kg}$ per day.

\section{Histopathology}

Renal biopsy was performed after a diagnosis of steroid resistance, or if the patient's age at onset of idiopathic nephrotic syndrome (INS) was more than 12 years. Repeat biopsy was performed if therapy toxicity was suspected. Biopsy specimens were processed using standard procedures that included hematoxylin-eosin, periodic acid-Schiff, and green Masson straining of formalin-included pieces. Immunofluorescence of frozen samples was carried out with a panel of antiserum protein antibodies against the immunoglobulins $\mathrm{A}, \mathrm{M}$ and $\mathrm{G}$ (IgA, $\operatorname{IgM}$, and $\operatorname{IgG}$ ) and the $3 \mathrm{rd}$ and 4 th complement components $\left(\mathrm{C}_{3}\right.$ and $\left.\mathrm{C}_{4}\right)$.

\section{Therapeutic protocol}

For our patients with ISRN, we adopted the protocol treatment established by the French Society of Pediatric Nephrology. ${ }^{1}$ CsA was given to all patients at an oral initial dose of
$150-200 \mathrm{mg} / \mathrm{m}^{2}$ body surface area per day (not exceeding $200 \mathrm{mg} / \mathrm{m}^{2}$ per day), in two equal doses. The dosage was adjusted to obtain trough concentrations between 100 and $150 \mathrm{ng} / \mathrm{mL}$, as measured by the monoclonal antibody radioimmunoassay on whole blood before the morning dose. CsA dosage was reduced by $20 \%$ if there was a decrease in creatinine clearance (calculated by the Schwartz formula) of more than $25 \%$. Prednisone was administered at a single dose of $30 \mathrm{mg} /$ $\mathrm{m}^{2}$ per day during the first month and then at the same dose, but on alternate days, for five months.

The therapeutic response was assessed four months after starting the treatment protocol. In patients who had not achieved complete or partial remission, the therapeutic regimen was stopped. If a remission had been obtained, the dose of prednisone was digressed and stopped within three months, and that of CsA was tapered and stopped within the following three months (the provided duration of treatment was 12 months).

When relapse occurred during the prednisone tapering phase, the patients were again treated with the initial combined therapy of CsA and prednisone. In cases of relapse during the CsA tapering phase, only CsA was re-introduced at the initial dosage for one month, and eventually prednisone was added when remission was not achieved. When a relapse occurred later than one month after the CsA therapy had been stopped, steroid responsiveness was tested again with oral prednisone therapy.

When CsA was impossible to continue, second line intravenous cyclophosphamide or Mycophenolate mofetil (MMF) was used.

\section{Follow-up}

All children were followed up every two weeks in the first month, and every month thereafter. The following measurements and laboratory tests were performed at each visit: body height and weight; blood pressure; complete blood cell count; serum creatinine; electrophoresis of proteins; serum cyclosporine level; and proteinuria.

\section{Statistical analysis}

We are interested mainly in the therapeutic response to CsA according to histological type and the fact that steroid resistance is initial or secondary. The statistical analysis was performed using the StatView software 5.0 (SAS Institute Inc., Cary, NC). Categorical variables were compared using the unpaired Student's $t$-test. Nominal variables were compared using chi square. A statistically significant difference was assumed when the $P$ value was less than 0.05 . 


\section{Results}

Thirty children with SRINS were analyzed during the study period. There were 19 males and 11 females. The mean age at the start of treatment was 8 years (range 1.4 to 14 years). Nineteen patients (63\%) were initially steroid-resistant and eleven patients $(37 \%)$ were secondary steroid-resistant. The first renal histopathology showed features suggestive of minimal change disease in nine patients $(30 \%)$, focal segmental glomerular sclerosis (FSGS) in 15 patients (50\%), and mesangioproliferative glomerulonephritis in six patients (20\%). During the first two weeks of treatment, the mean oral dose of CsA was $165 \mathrm{mg} / \mathrm{m}^{2}$ per day and the mean whole blood trough level was $141 \mathrm{ng} / \mathrm{mL}$.

Six patients (20\%) showed no response to therapy. The use of cyclophosphamide and MMF did not give a satisfactory response. All these patients have since progressed to chronic renal failure, with the exception of one patient, who presented a remission under inhibitors of angiotensinconverting enzyme, which still maintains normal renal function after a decline of five years.

Fifteen patients (50\%) achieved complete remission and partial remission was achieved in nine patients (30\%). The overall response (complete or partial remission), regardless of pathological types, was $80 \%$. The remission was achieved during the first month of treatment in $25 \%(6 / 24)$ of patients; during the second month in 33\% of patients $(8 / 24)$; during the third month in $33 \%(8 / 24)$ of patients; and during the forth month in $8 \%$ of patients $(2 / 24)$.

Also, the response to treatment was analysed according to various parameters: age, sex, initially or secondary steroid resistance, and pathological type (Table 1). We did not find

Table I Therapeutic response to cyclosporine A ( $C s A)$ according to age, clinical presentation, sex, and histological types

\begin{tabular}{lllll}
\hline & & \multicolumn{2}{l}{ Response to CsA } & \\
\cline { 3 - 4 } & & $\begin{array}{l}\text { Responders } \\
(\mathbf{n}=\mathbf{2 4})\end{array}$ & $\begin{array}{l}\text { Non-responders } \\
(\mathbf{n}=6)\end{array}$ & P-value \\
\hline $\begin{array}{l}\text { Mean age in months } \\
\text { (range) }\end{array}$ & $86.0(17-168)$ & $86.5(4 \mid-168)$ & 0.98 I \\
Sex & $M$ & $16(84 \%)$ & $3(16 \%)$ & \\
Steroid & F & $8(73 \%)$ & $3(27 \%)$ & 0.64 I \\
resistance & Secondary & $10(91 \%)$ & I (9\%) & 0.372 \\
Histopathology & MCD & $7(78 \%)$ & $2(22 \%)$ & 0.966 \\
& FSGS & $12(80 \%)$ & $3(20 \%)$ & \\
& PMD & $5(83 \%)$ & I (17\%) & \\
\hline
\end{tabular}

Abbreviations: $M$, male; $F$, female; $C s A$, cyclosporine $A ; M C D$, minimal change disease; FSGS, focal segmental glomerular sclerosis; PMD, diffuses mesangiale proliferation. a statistically significant relationship between the different parameters tested and the response to CsA.

At the sixth month of treatment, there was no significant rate of hypertension. One patient required the use of angiotensin-converting enzyme inhibitors. Six patients were already hypertensive before starting treatment. The creatinine clearance according to the Schwartz formula was not significantly different compared to the baseline creatinine clearance. At month 24, patients with complete remission maintained a normal creatinine level. For patients with partial remission, the outcome was marked by impaired renal function in four patients, 9, 12, 13, and 15 months respectively after the onset of treatment. Renal biopsy was performed in all cases and showed pathological findings compatible with natural course of SRNS in three patients and intense interstitial fibrosis in one case. In this last patient, CsA was replaced by MMF, which permeated to maintain a partial remission and a rapid improvement of renal function. With the exclusion of this patient, the other three patients progressed to end-stage renal disease occurring between the 16th and 36th months.

Cosmetic adverse events were observed with varying proportions: hypertrichosis in $60 \%$ of cases; gingival hypertrophy in $27 \%$; and tremors in $11.5 \%$. The first side-effect to appear was the tremor followed by hypertrichosis.

Among the 15 patients with complete remission, eight patients maintained this response even after discontinuation of the therapeutic protocol and five patients experienced a relapse six months after the start of treatment. Two patients had a relapse three and five months, respectively, after the stopping of CsA. Corticosteroid therapy alone was tried in both but only one patient had a good response. The other patient received the same protocol again for two years.

\section{Discussion}

In childhood ISRNS, CsA remains the first-line therapy. The mechanism by which CsA induces remission of proteinuria remains incompletely elucidated. The interleukin-2-inhibiting action may not explain all effects of CsA. ${ }^{3}$ A non-immunologic mechanism is quite plausible. ${ }^{4}$ Used alone, CsA has allowed a complete remission in a small proportion of patients; ${ }^{5}$ however, since its use combined with prednisone, it has offered a better therapeutic response. In the collaborative study of Niaudet et al using CsA in combination with prednisone, approximately $50 \%$ of patients had a remission which was complete in most cases. ${ }^{1}$ The dosage of prednisone used in combination with CsA varies according to studies. Gregory et $\mathrm{al}^{6}$ used 
an alternate day prednisone dose of $2 \mathrm{mg} / \mathrm{kg}$ in his study and obtained a remission rate of $86 \%$. However, when using a low dose of prednisone, the therapeutic response appears to be lower, as reported by Hymes. ${ }^{7}$ Also, the use of intravenous methyl-prednisolone (MTP) associated to CsA may not improve the rate of remission. The idea of combining CsA, MTP and prednisone appears to offer a better therapeutic approach. Waldo ${ }^{8}$ and later Ehrich ${ }^{9}$ reported, in two retrospective studies of children with focal segmental hyalinosis and treated with cyclo-MPTprednisone, high rates of complete remission ranging between 84 and $90 \%$. Hamasaki, ${ }^{2}$ in his retrospective study, used methylprednisolone pulse therapy in addition to CsA and prednisone in patients with FSGS. The results of this protocol treatment were encouraging with a response rate of around $85.7 \%$. However, the number of patients reported in this study was small (seven) and so valid conclusions cannot be drawn. In summary, all these studies have suggested that CsA improves steroid sensitivity in steroidresistant nephrotic children and recommend the use of combination cyclosporine-prednisone in the management of steroid-resistant nephrotic syndrome.

The initial dose of CsA has been variably expressed either in $\mathrm{mg} / \mathrm{kg}$ or $\mathrm{mg} / \mathrm{m}^{2}$ body surface area. The trough level recommended by most authors varies from 100 to $150 \mathrm{ng} / \mathrm{mL}$ during the first three months, and between 60 and $100 \mathrm{ng} / \mathrm{mL}$ later, when remission is achieved. ${ }^{1,2,10}$ The majority of CsA-responsive patients experience remission during the first three months of treatment. In the present study, most patients who attained partial or complete remission did so after three months of treatment.

The duration of treatment with CsA is difficult to predict. It depends on the therapeutic response obtained and tolerance. The risk of cyclo-dependence and frequent relapse is real, leading to prolonged treatment for several years. ${ }^{11}$ In patients who fail to show any reduction of proteinuria at the end of six months of treatment, no significant benefit is expected later. A difficult question is when to abandon CsA treatment and declare a patient as a non-responder to this drug. A trial period of six months is commonly used. ${ }^{12}$

Considering the histological type, Hymes ${ }^{7}$ found that the overall response to CsA is very similar in the three histological types. However, the rate of complete remission is frequently observed during the 'minimal change disease' (MCD) condition. The partial remission is more frequent in the FSGS and 'diffuses mesangiale proliferation' (DMP) conditions. In our study, there was no significant difference in response to CsA, regardless of the histology
$(P=0.212): 78 \%$ for MCD and $80 \%-83 \%$ for FSGS and DPM. On the other hand, Niaudet ${ }^{1}$ obtained a poorer response in patients with FSGS compared with those with MCD (51.5\% vs $40 \%)$. Hamasaki et $\mathrm{al}^{2}$ administered the bolus MTP in addition to CsA and prednisone, to maximize the rate of remission in patients with FSGS and achieved a remission rate of $85.7 \%$.

The nephrotoxicity is the main side-effect of CsA, which may contribute to the progression towards chronic renal failure. ${ }^{13}$ It must be detected by routine pathological study after two years of treatment, even in patients who maintain a normal creatinine clearance. ${ }^{14}$ To evaluate the nephrotoxicity in children with ISRNS, Hamasaki ${ }^{2}$ performed a systematic renal biopsy after 12-24 months of treatment. Among 26 patients, he noted only one with CsA-related nephrotoxicity. This low rate of nephrotoxicity was attributed to an adequate monitoring of the CsA dosage. Similar findings have been objectified in our study, although we did achieve a renal biopsy in only a small proportion of patients. The nephrotoxicity related to CsA does not appear to be higher than that related to tacrolimus. In a recent comparative study, we did not identify a difference in terms of efficacy or nephrotoxicity, but cosmetic side-effects and hypertension were rarely observed with tacrolimus. ${ }^{15}$ Nephrotoxicity related to CsA appears to be dose-dependent. A low-dose CsA, administered for a period exceeding four years, seems safe, as evidenced by the study of Ghiggeri et a ${ }^{16}$ involving children with FSGS. Moreover, nephrotoxicity related to CsA may be reduced by several agents, such as vitamin E and corticosteroids, which have a suppressive effect on CsAinduced apoptosis. ${ }^{17,18}$ When CsA is impossible to continue because of its nephrotoxicity, the switch may be provided by the MMF. ${ }^{19}$ This agent is able to maintain remission with rapid improvement of renal function. Moreover, if nephrotic syndrome persists under CsA therapy, there are no effective therapeutic alternatives besides the current tests involving rituximab whose results are so far promising. ${ }^{20}$ This new therapeutic approach must however undergo testing in randomised prospective clinical trials.

\section{Conclusion}

Presently, a combination therapy composed of CsA and prednisone appears to be the most promising strategy to adopt in childhood ISRNS. However, the long-term CsA therapy may be complicated by renal tubulointerstitial fibrosis leading to the use of other non-nephrotoxic immunosuppressive agents. MMF in this situation is a good therapeutic alternative, able to maintain the therapeutic response without nephrotoxicity. 


\section{Disclosure}

The authors report no conflicts of interest in this work.

\section{References}

1. Niaudet P. Treatment of childhood steroid-resistant idiopathic nephrosis with a combination of cyclosporine and prednisone. J Pediatr. 1994;126:981-986.

2. Hamasaki Y, Yoshikawa N, Hattori S, et al. Cyclosporine and steroid therapy in children with steroid-resistant nephrotic syndrome. Pediatr Nephrol. 2009;24:2177-2185.

3. Gipson DS, Massengill SF, Yao L, et al. Management of childhood onset nephrotic syndrome. Pediatrics. 2009;124:747-757.

4. Meyrier AY. Treatment of focal segmental glomerulosclerosis with immunophilin modulation: when did we stop thinking about athogenesis? Kidney Int. 2009;76:487-491.

5. Singh A, Tejani C, Tejani A. One-center experience with cyclosporine in refractory nephrotic syndrome in children. Pediatr Nephrol. 1999; 13:26-32.

6. Gregory MJ, Smoyer WE, Sedman A, et al. Long-term cyclosporine therapy for pediatric nephrotic syndrome: a clinical and histologic analysis. J Am Soc Nephrol. 1996;7:543-549.

7. Hymes LC. Steroid-resistant, cyclosporine-responsive, relapsing nephrotic syndrome. Pediatr Nephrol. 1995;9:137-139.

8. Waldo FB, Benfield MR, Kohaut EC. Methylprednisolone treatment of patients with steroid-resistant nephrotic syndrome. Pediatr Nephrol. 1992;6:503-505.

9. Ehrich JH, Geerlings C, Zivicnjak M, Franke D, Geerlings H, Gellermann J. Steroid-resistant idiopathic childhood nephrosis: overdiagnosed and undertreated. Nephrol Dial Transplant. 2007;22: 2183-2193.

10. Naito M, Takei T, Eguchi A, Uchida K, Tsuchiya K, Nitta K. Monitoring of blood cyclosporine concentration in steroid-resistant nephrotic syndrome. Inter Med. 2008;47:1567-1572.
11. Cattran DC, Alexopoulos EH, Heering P, et al. Cyclosporin in idiopathic glomerular disease associated with the nephrotic syndrome: workshop recommendations. Kidney Int. 2007;72:1429-1447.

12. Burgess E. Management of focal segmental glomerulosclerosis: evidence-based recommendations. Kidney Int Suppl. 1999;70: S26-S32.

13. Kengne-Wafo S, Massella L, Diomedi-Camassei F, et al. Risk factors of cyclosporin A nephrotoxicity in children with steroid-dependant nephrotic syndrome. Clin J Am Soc Nephrol. 2009;4:1409-1416.

14. Habib R, Niaudet P. Comparison between pre and post treatment renal biopsies in children receiving cyclosporine for idiopathic nephrosis. Clin Nephrol. 1994;42:141-146.

15. Choudhry S, Bagga A, Hari P, Sharma S, Kalaivani M, Dinda A. Efficacy and safety of tacrolimus versus cyclosporine in children with steroid-resistant nephrotic syndrome: a randomized controlled trial. Am J Kidney Dis. 2009;53(5):760-769.

16. Ghiggeri GM, Catarsi P, Scolari F, et al. Cyclosporine in patients with steroid-resistant nephrotic syndrome: an open-label, nonrandomized, retrospective study. Clin Ther. 2004;26:1411-1418.

17. Jeon SH, Piaco YJ, Choi KJ, et al. Prednisolone suppresses cyclosporin A-induced apoptosis but not cell cycle arrest in MDCK cells. Arch Biochem Biophys. 2005;435:382-392.

18. Arriba G, Hornedo JP, Rubio SR, et al. Vitamin E protects against the mitochondrial damage caused by cyclosporin A in LLC-PK1 cells. Toxicol Appl Pharmacol. 2009;239:241-250.

19. Ulinski T, Dubourg L, Said MH, et al. Switch from cyclosporine A to mycophenolate mofetil in nephrotic children. Pediatr Nephrol. 2005;20:482-485.

20. Haffner D, Fischer DC. Nephrotic syndrome and rituximab: facts and perspectives. Pediatr Nephrol. 2009;24:1433-1438.

\section{Publish your work in this journal}

The International Journal of Nephrology and Renovascular Disease is an international, peer-reviewed open-access journal focusing on the pathophysiology of the kidney and vascular supply. Epidemiology, screening, diagnosis, and treatment interventions are covered as well as basic science, biochemical and immunological studies. The journal welcomes

\section{Dovepress}

original research, clinical studies, reviews \& evaluations, expert opinion and commentary, case reports and extended reports. The manuscript management system is completely online and includes a very quick and fair peerreview system, which is all easy to use. Visit http://www.dovepress.com/ testimonials.php to read real quotes from published authors. 